\title{
Prioritization of Attributes for Palletizing Robots in Beverage Industry of Pakistan
}

\author{
BILAL AHMED*, HAFIZ MUHAMMAD KHURRAM ALI*, AMIR SULTAN*, AND \\ BAKHT BAHADUR RANA** \\ RECEIVED ON 11.02.2016 ACCEPTED ON 11.05.2016
}

\begin{abstract}
Robots are extensively used in modern manufacturing industries to perform numerous repetitive operations. The challenge of selecting the most appropriate robot for a particular manufacturing setup is progressively becoming complex as there are numerous selection criteria and more alternatives available in market. Only a limited amount of research is available in literature which focuses on the selection of industrial robots for beverage industry. This study offers a country specific application of AHP (Analytical Hierarchy Process) in problem of palletizing robot selection for beverage industry of Pakistan. The problem is structured in standard AHP hierarchy and equations. The factors initially explored from the concerned literature are prioritized by the industry experts. The available robot alternatives are evaluated for each parameter and results are computed with the help of Exert Choice, a commercial AHP software. It is observed that experts in Pakistan beverage industry are very sensitive to operating costs of the robots and they do not assign as much weightage to technical parameters like repeatability and programmability. The robots with lesser associated costs and better speed and 'manipulator reach' are higher in ranking. The findings are beneficial for the international investors and local beverage industry managers to corroborate the current trends and preferences of the said industry.
\end{abstract}

Key Words: Multi-Criteria Decision Making, Analytical Hierarchy Process, Palletizing Robot, Beverage Industry

\section{INTRODUCTION}

I ndustrial robot is a high level automated system programmed to perform a range of industrial operations. The utilization of industrial robots has increased to a significant level due to considerable evolution in engineering and manufacturing industry in the past few decades. The prominent features of industrial robots which make them unsurpassed substitute to human activity for accomplishing industrial operations are their reprogramming ability, accuracy and operating speeds etc.

Robots can be programmed to work in different scenarios requiring different operating parameters. Fully automated industrial robots have decision making capacity induced through artificial intelligence which enables them to respond to different sensory inputs. Owing to the

\footnotetext{
* Department of Mechatronic Engineering, University of Engineering \&Technology, Taxila, Sub-Campus Chakwal.

** $\quad$ Glass \& Ceramics Research Centre, PCSIR Labs, Lahore.
}

Mehran University Research Journal of Engineering \& Technology, Volume 36, No. 3, July, 2017 [p-ISSN: 0254-7821, e-ISSN: 2413-7219] 
multifunctioning attributes of the manufacturing setup, beverage industries utilize robots for performing numerous operations like material handling, quality assurance, packing of products and palletizing operations.

One of the important applications of the robots in beverage industries is palletizing operation in which stacks or pallets are made in predefined arrangement making the product ready for transportation. Installing robots for palletizing operations is an economic way of productivity enhancement. It also reduces the effect of fatigue involved in case of repetitive maneuvors done manually.

Selecting the best robot for a specific application is an important decision for the management in the beverage industry. Several alternatives are available and there exists a large number of attributes which influence the selection decision. While selecting a palletizing robot for beverage industry, it is inevitable for the decision makers to explore and prioritize these attributes or parameters. Degrees of freedom, manipulator reach, programming flexibility and associated costs are the few instances of these attributes. Since multiple robot options are available for beverage industry and there is a broad variety of influencing attributes, this problem lies under the category of MCDM (Multi-Criteria Decision Making).

MCDM models are applied only if there are multiple influencing parameters and multiple alternatives [1]. These methods are either compensatory or non-compensatory. In non-compensatory methods, there are no mutual flexibilities among the parameters whereas compensatory methods permit some trade-off's [2,3]. Some of the common characteristics which are shared among all MCDM methodologies include multiple objectives, conflicting criteria, different measuring units for the attributes and alternative rankings [4]. Among MCDM techniques, AHP is used most widely. It involves pairwise comparisons of attributes and alternatives which are accomplished by experts of the concerned industry [5].
Despite the fact that robot selection is a complex, cost intensive and irreversible MCDM decision, most of the studies reported in available literature present different other techniques like performance optimization and statistical methods for decisions of industrial robot selection. Only a few researchers utilized some MCDM models. These models normally include both subjective and objective types of attributes [6].

In addition to AHP, some authors have also applied other MCDM techniques like DEA (Data Envelopment Analysis) [7], TOPSIS [8] and graphical methods [9] etc. Recently researchers have started utilizing hybrid methodologies by combining multiple techniques like fuzzy TOPSIS [10], fuzzy-QFD (Quality Function Deployment) [11] and fuzzyAHP [12]. Most of the research on robots covers their design and planning aspects [13,14]. There are hardly any studies found in literature which emphasize on MCDM perspective of beverage industry palletizing robots particularly in current industrial perspective of Pakistan.

One problem with most of the MCDM techniques is that the data collection from experts is vague and substantial computational efforts are involved. In MCDM problems, the expert opinion is normally required from executive managers who have very busy schedules. AHP requires managers to compare only two parameters at a time which is very convenient and straight forward for these senior professionals. Moreover, AHP is backed by authentic mathematical models founded on matrix algebra which are developed, modified and implemented in other similar fields by scientists and researchers $[3,15,16]$. The current paper, therefore, utilizes the AHP modelling for selection of palletizing robot in beverage industry of Pakistan.

Next section of this paper offers the general mathematical models constituted for this robot selection problem. The models are simulated in section 3. Quantitative results are presented and discussed in section 4 followed by the concluding section. 


\section{THE AHP MODELLING}

The standard AHP model presented by Saaty [5] is used in this study to model the problem for selection of suitable robot. After defining our problem next step involves the determination of variables and candidate alternatives which we intend to prioritize on the basis of predefined criteria. Hierarchy is then constructed which includes goal, selection criteria and candidate alternatives. The main feature of AHP is pairwise comparison of selection criteria. Each factor is compared with every other factor in terms of their relative importance. Relative importance between each pair of decision criteria and alternatives are rated. This requires services of the experts of the related industry and Saaty's scale of 1-9 is used for prioritization process. The output of AHP is set of priorities of alternatives which is calculated by first constructing the decision matrix and then calculating the weights of all factors and alternatives.

This decision matrix " $A$ " is a square matrix and every element of this square matrix represents the pair wise comparison of $\mathrm{i}^{\text {th }}$ element with respect to $\mathrm{j}^{\text {th }}$ element by assigning the numeric values from 1-9. When a factor is compared to itself, it yields the numeric value ' 1 ' in the decision matrix. Moreover, the value of an element of decision matrix will be inverse if the two criteria already compared are again subjected to pairwise comparison in reverse order arrangement. Equation (1) shows the decision matrix for a problem having $\mathrm{n}$ number of factors involved[5,17,18].

$$
A=\left[a_{i j}\right]_{n \times n}=\left[\begin{array}{cccc}
a_{11} & a_{12} & \cdots & a_{1 n} \\
a_{21} & a_{22} & \cdots & a_{2 n} \\
\cdot & \cdot & \cdot & \cdot \\
a_{n 1} & a_{n 2} & \cdots & a_{n n}
\end{array}\right]
$$

The calculation of the weights matrix is the next logical step. Weights can be calculated using the eigenvalue method. This method was used by Saaty for determination of weights vector [5]. To calculate these weights, we first need to normalize matrix A using Equation (2).

$$
a_{i n}^{*}=\frac{a_{i j}}{\sum_{i=1}^{n} a_{i j}}
$$

where 'i' and 'j' are 1, 2, 3, .., n

After normalizing the comparison matrix ' $A$ ', final priority weights are calculated using Equation (3).

$w_{i}=\frac{\sum_{j=1}^{n} a_{i j}^{*}}{n}$

where 'i’ and 'j’ are 1, 2, 3, .., n

\section{MODEL SIMULATION}

To reduce the computational effort and have a sensitivity analysis, the AHP software Expert Choice ${ }^{\circledR}$ has been utilized. An initial un-prioritized list of main factors and sub factors has been prepared from the relevant literature and presented to a panel of experts from Pakistan beverage industry. Experts agreed to keep all the factors in same category rather than grouping them into main and sub factors so that all the factors are analyzed at the same level and we can have a deep insight of every individual factor and its influence on the ranking of the robots. Screened out eight factors are shown in the AHP hierarchy presented in Fig. 1.

These factors can be classified into different categories like beneficial or non-beneficial, subjective or objective, etc. If the higher values of factors are desirable, they are termed as beneficial ones, e.g. work load capacity, manipulator reach, etc. When we are interested in lower value, the factors will be called non-beneficial attributes, e.g. costs, error in repeatability, etc. The attributes which can be defined numerically are classified as objective attributes, e.g. costs, manipulator reach, etc., whereas the attributes that are qualitative in nature are subjective attributes, e.g. programming flexibility, etc.The factor 'Operating Costs’ comprises all running and maintenance costs including the cost associated with setup time of 
robots.Investment costs include purchasing, transportation and installation costs. Speed, work load, manipulator reach, memory capacity, programmability and repeatability are the other selected factors. Repeatability is the ability of robot to move its end-effector to a same position over repetitive time periods with little error. Speed is the maximum velocity with which the robot can move its tip in its workspace. Flexibility in programming ability of the robot is the ease with which the robot has tendency to be reprogrammed. Workload capacity is the maximum load that an end-effector of robot can bear without any damage.

Another important attribute while choosing a suitable robot is its ability to store data points while executing the operation. This is termed as 'memory capacity' of the robot [9,10].Workload capacity, speed, manipulator reach, programmability and memory capacity are beneficial attributes as their maximum value is desirable. Investment costs, operating costs and repeatability are the nonbeneficial or undesirable attributes as their minimum value is required. Error in repeatability is undesirable as minimum error is desirable for the particular robotic application in industry.
A standard AHP questionnaire adapted fromTomar, and Borad [19] has been developed for pairwise comparison of factors using Satay's scale of 1-9 and presented to the experts of beverage industry. A sample from actual questionnaire is presented in Appendix-I. Researchers in the area of AHP preferably take a small sample size of experts as it has more practical worth than a large sample size [20,21]. This is because of the fact that chances of getting arbitrary and inconsistent answers are increased if a large number of pairwise comparisons are collected, thus leading to mathematically unrealistic result [22]. Unlike statistical techniques, AHP normally does not prefer a large sample size from a big population rather it prefers a smaller one. However, the selected experts must have concrete knowledge and expertise in the chosen field of study. Most of the researchers in similar fields, therefore, normally keep the number of experts lesser than ten. For instance, there were a total of ten experts in studies performed by Cheng and $\mathrm{Li}$ [20] and Wong and $\mathrm{Li}$ [22] while eight experts were approached by Lam and Zhao [21]. A sample size of three experts from a single industry has been used by Tahriri et al. [23]. In our current research, six top level managers with strong technical and managerial expertise in concerned field from a well-known

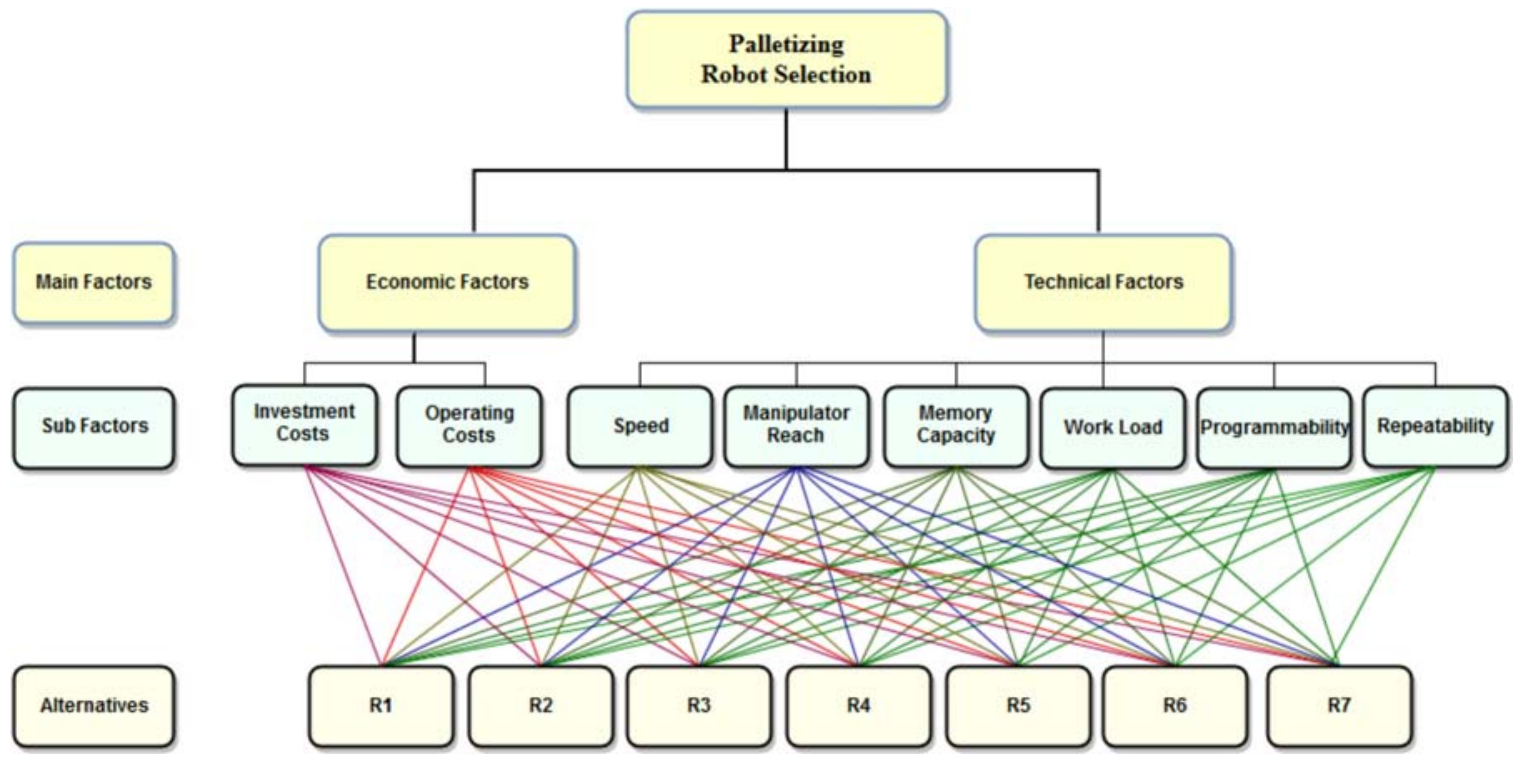

FIG. 1. AHP HIERARCHY FOR ROBOT SELECTION PROBLEM 
beverage industry of Pakistan had been interviewed. Each factor is compared with other factors by the decision makers through pairwise comparison. Priority weights based on decision makers' preferences of all the factors are thus calculated using the mathematical models presented in previous section.

\begin{tabular}{|c|c|c|c|c|c|}
\hline \multicolumn{6}{|c|}{ APPENDIX-I. QUESTIONNAIRE } \\
\hline \multicolumn{3}{|l|}{ Name of the Expert: } & \multicolumn{3}{|l|}{ Designation: } \\
\hline \multicolumn{6}{|c|}{$\begin{array}{l}\text { Please compare the importance of the elements in relation to the objective and fill in the table. Which element of each pair is } \\
\text { more important, A or B and how much more on a Scale 1-9 as given below: }\end{array}$} \\
\hline \multirow{2}{*}{$\mathrm{i}$} & \multirow{2}{*}{$\mathrm{j}$} & \multicolumn{2}{|c|}{ Criteria } & \multirow{2}{*}{$\begin{array}{c}\text { More Importance? } \\
\text { A or B }\end{array}$} & \multirow{2}{*}{$\begin{array}{l}\text { Scale } \\
(1-9)\end{array}$} \\
\hline & & A & B & & \\
\hline 1 & 2 & \multirow{7}{*}{ Investment Costs } & Operating Costs & & \\
\hline 1 & 3 & & Error in Repeatability & & \\
\hline 1 & 4 & & Speed & & \\
\hline 1 & 5 & & Memory Capacity & & \\
\hline 1 & 6 & & Work Load & & \\
\hline 1 & 7 & & Manipulator Reach & & \\
\hline 1 & 8 & & Programmability & & \\
\hline 2 & 3 & \multirow{6}{*}{ Operating Costs } & Error in Repeatability & & \\
\hline 2 & 4 & & Speed & & \\
\hline 2 & 5 & & Memory Capacity & & \\
\hline 2 & 6 & & Work Load & & \\
\hline 2 & 7 & & Manipulator Reach & & \\
\hline 2 & 8 & & Programmability & & \\
\hline 3 & 4 & \multirow{5}{*}{ Error in Repeatability } & Speed & & \\
\hline 3 & 5 & & Memory Capacity & & \\
\hline 3 & 6 & & Work Load & & \\
\hline 3 & 7 & & Manipulator Reach & & \\
\hline 3 & 8 & & Programmability & & \\
\hline 4 & 5 & \multirow{4}{*}{ Speed } & Memory Capacity & & \\
\hline 4 & 6 & & Work Load & & \\
\hline 4 & 7 & & Manipulator Reach & & \\
\hline 4 & 8 & & Programmability & & \\
\hline 5 & 6 & \multirow{3}{*}{ Memory Capacity } & Work Load & & \\
\hline 5 & 7 & & Manipulator Reach & & \\
\hline 5 & 8 & & Programmability & & \\
\hline 6 & 7 & \multirow{2}{*}{ Work Load } & Manipulator Reach & & \\
\hline 6 & 8 & & Programmability & & \\
\hline 7 & 8 & Manipulator Reach & Programmability & & \\
\hline Intensity of Importance & \multicolumn{2}{|c|}{ Definition } & \multicolumn{3}{|c|}{ Explanation } \\
\hline 1 & & & \multicolumn{3}{|c|}{ Two elements contribute equally to the objective } \\
\hline 3 & & & \multicolumn{3}{|c|}{ Experience and judgment slightly favor one element over another } \\
\hline 5. & & & \multicolumn{3}{|c|}{ Experience and judgment strongly favor one element over another } \\
\hline 7. & & & \multicolumn{3}{|c|}{$\begin{array}{l}\text { One element is favored very strongly over another, its dominance is } \\
\text { demonstrated in practice }\end{array}$} \\
\hline 9. & & & \multicolumn{3}{|c|}{$\begin{array}{l}\text { The evidence favoring one element over another is of the } \\
\text { highest possible order of affirmation }\end{array}$} \\
\hline
\end{tabular}

Mehran University Research Journal of Engineering \& Technology, Volume 36, No. 3, July, 2017 [p-ISSN: 0254-7821, e-ISSN: 2413-7219] 
Keeping in view the minimum selection constraints of the problem, seven robots manufactured by different international firms have been selected as candidate alternatives. All of the alternatives are specifically designed for performing pick and place (palletizing) operation. Makes and Models of these robot alternatives are provided in Appendix-II. Quantitative data for these alternatives is collected from the concerned manufacturers. Data for the subjective factor "Programmability" has been collected from industry experts. The weights for this subjective factor are calculated using standard pairwise comparison matrices. The data for objective factors is summarized in Table 1.

The economic factors have attained the highest proportion, implying that the decision makers in the

\begin{tabular}{|c|c|}
\hline \multicolumn{2}{|c|}{ APPENDIX-II. ROBOT MAKES/MODEL } \\
\hline Robot Alternatives & Manufacturer/Models \\
\hline R1 & ASEA-IRB 60/2 \\
\hline R2 & Cincinnati Milacrone T3-726 \\
\hline R3 & Cybotech V15 Electric Robot \\
\hline R4 & Hitachi America Process Robot \\
\hline R5 & Unimation PUMA 500/600 \\
\hline R6 & Unimation PUMA 500/600 \\
\hline R7 & Yaskawa Electric Motoman L3C \\
\hline
\end{tabular}

beverage industry in Pakistan are cost sensitive. Operating costs have got more importance than investment costs. Though technical parameters are very crucial and inevitable for a complete evaluation of the robots, they have emerged as relatively less important factors for our comparisons. It is evident from Fig. 2 that economic factors have dominated the pie chart. To have a more detailed insight about the technical factors a second iteration of the pairwise comparisons has been performed with the help of experts. In this round, only technical factors are re-evaluated to check their relative importance with eachother.

Weights obtained for the technical factors in this second round are shown in Fig. 3. Speed and manipulator reach have got the highest weights while repeatability and programmability are at the bottom of the list. It can be concluded from above discussion that economic factors are the most crucial ones in perspective of current needs of Pakistan beverage industry. Using the data compiled in Table 1 and the priority weights shown in Figs. 2-3 the weights for robot alternatives are computed in Expert Choice $^{\circledR}$ software(available at www.expertchoice.com). Fig. 4 shows the final priority wise ranking of all the Robot alternatives.

TABLE 1. QUANTITATIVE DATA OF THE SEVEN ROBOT ALTERNATIVES.

\begin{tabular}{|c|c|c|c|c|c|c|c|}
\hline & $\mathrm{R} 1$ & $\mathrm{R} 2$ & $\mathrm{R} 3$ & $\mathrm{R} 4$ & $\mathrm{R} 5$ & $\mathrm{R} 6$ & $\mathrm{R} 7$ \\
\hline Investment Cost (\$) & 1700 & 1000 & 1300 & 950 & 700 & 900 & 500 \\
\hline Operating Costs (\$) & 170 & 150 & 100 & 140 & 150 & 120 & 100 \\
\hline $\begin{array}{c}\text { Repeatability } \\
\text { (Error in mm) }\end{array}$ & 0.4 & 0.15 & 0.1 & 0.2 & 0.1 & 0.08 & 0.1 \\
\hline Speed (mm/s) & 2540 & 1016 & 1272.2 & 1000 & 560 & 1016 & 177 \\
\hline $\begin{array}{c}\text { Memory Capacity (cycles } \\
\text { per second) }\end{array}$ & 500 & 3000 & 1500 & 2000 & 500 & 350 & 1000 \\
\hline Workload (Kg) & 60 & 6.35 & 6.8 & 10 & 2.5 & 4.5 & 3 \\
\hline Manipulator Reach (mm) & 990 & 1041 & 1676 & 965 & 915 & 508 & 920 \\
\hline
\end{tabular}

Mehran University Research Journal of Engineering \& Technology, Volume 36, No. 3, July, 2017 [p-ISSN: 0254-7821, e-ISSN: 2413-7219] 
Alternative'R7' which is basically a palletizing robot manufactured in Japan has got the highest ranking among all other robots. R3 has obtained the second highest priority despite having a higher initial investment cost. The other robots are mostly manufactured in USA or Sweden. To have a more detailed elaboration of the effects of all factors on the alternatives the performance of alternatives with respect to each factor is drawn in Fig. 5.

Though the alternative R3, a robot manufactured by a Swedish firm, has very good speed and workload capacity, it has achieved lowest ranking mainly due to very high investment and operating costs.

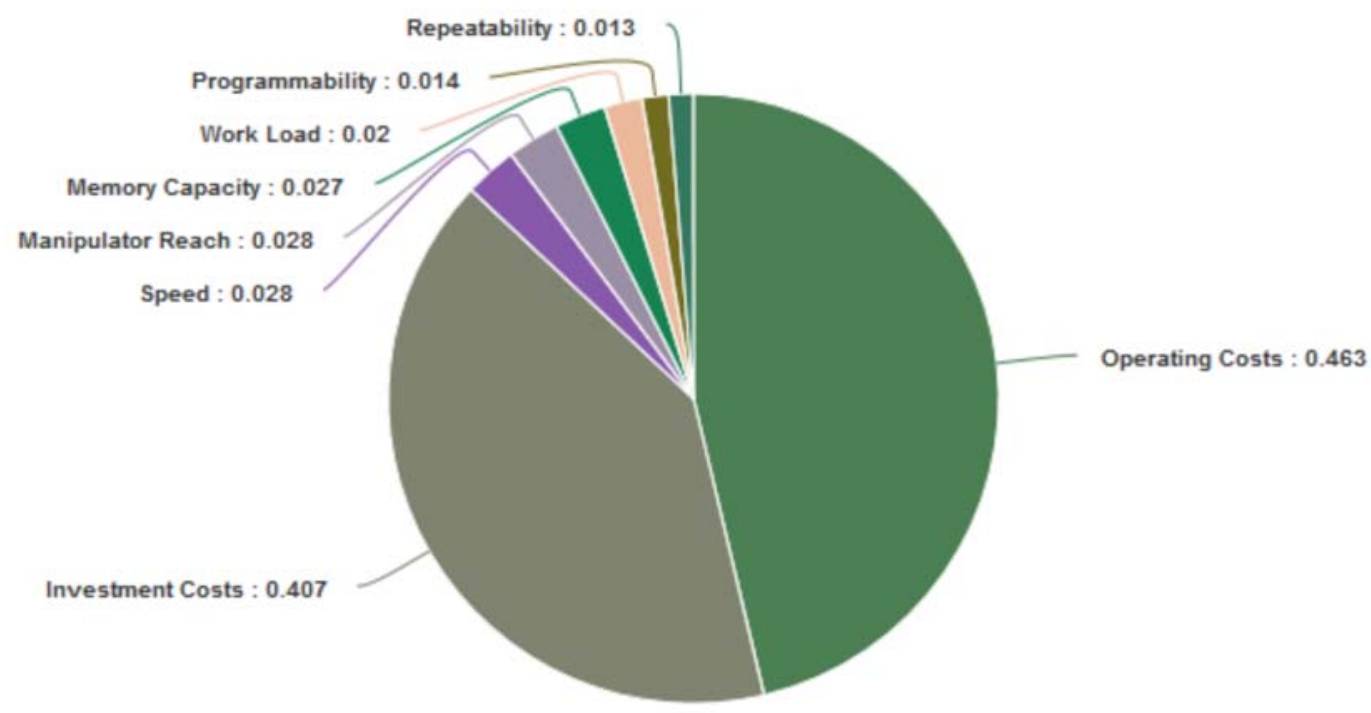

FIG. 2. PRIORITY WEIGHTS OF ALL FACTORS

Speed

Manipulator Reach

Workload

Memory Capacity

Programmability

Repeatability

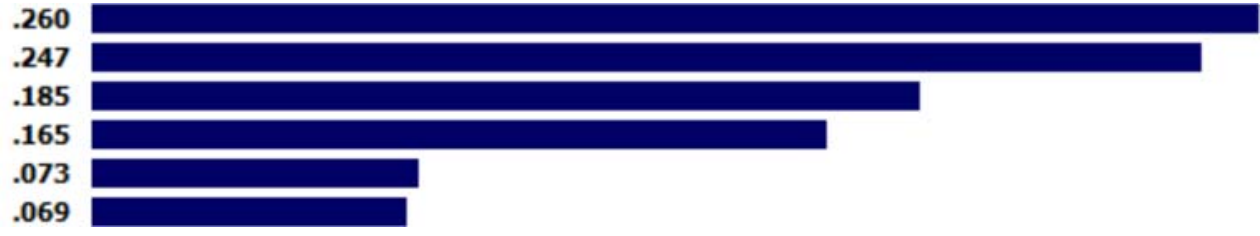

FIG. 3. WEIGHTS FOR TECHNICAL FACTORS

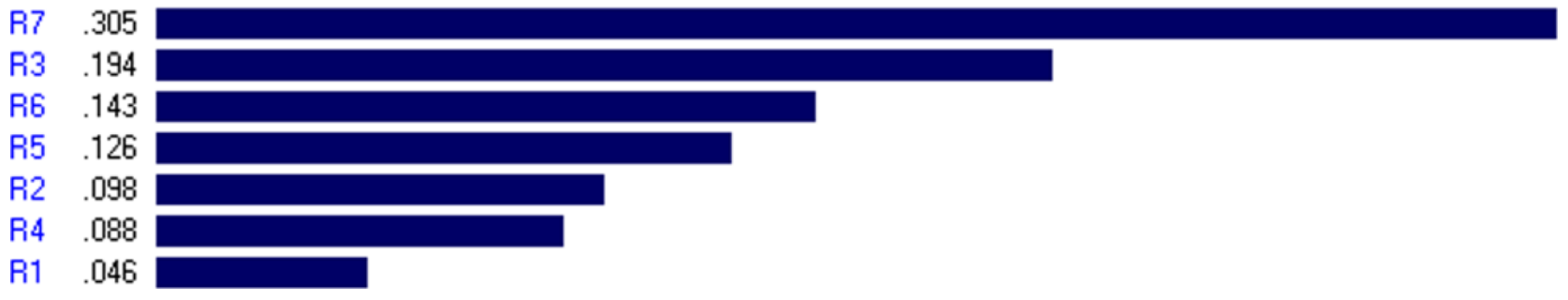

FIG. 4. OVERALL RANKING OF ROBOTALTERNATIVES

Mehran University Research Journal of Engineering \& Technology, Volume 36, No. 3, July, 2017 [p-ISSN: 0254-7821, e-ISSN: 2413-7219] 


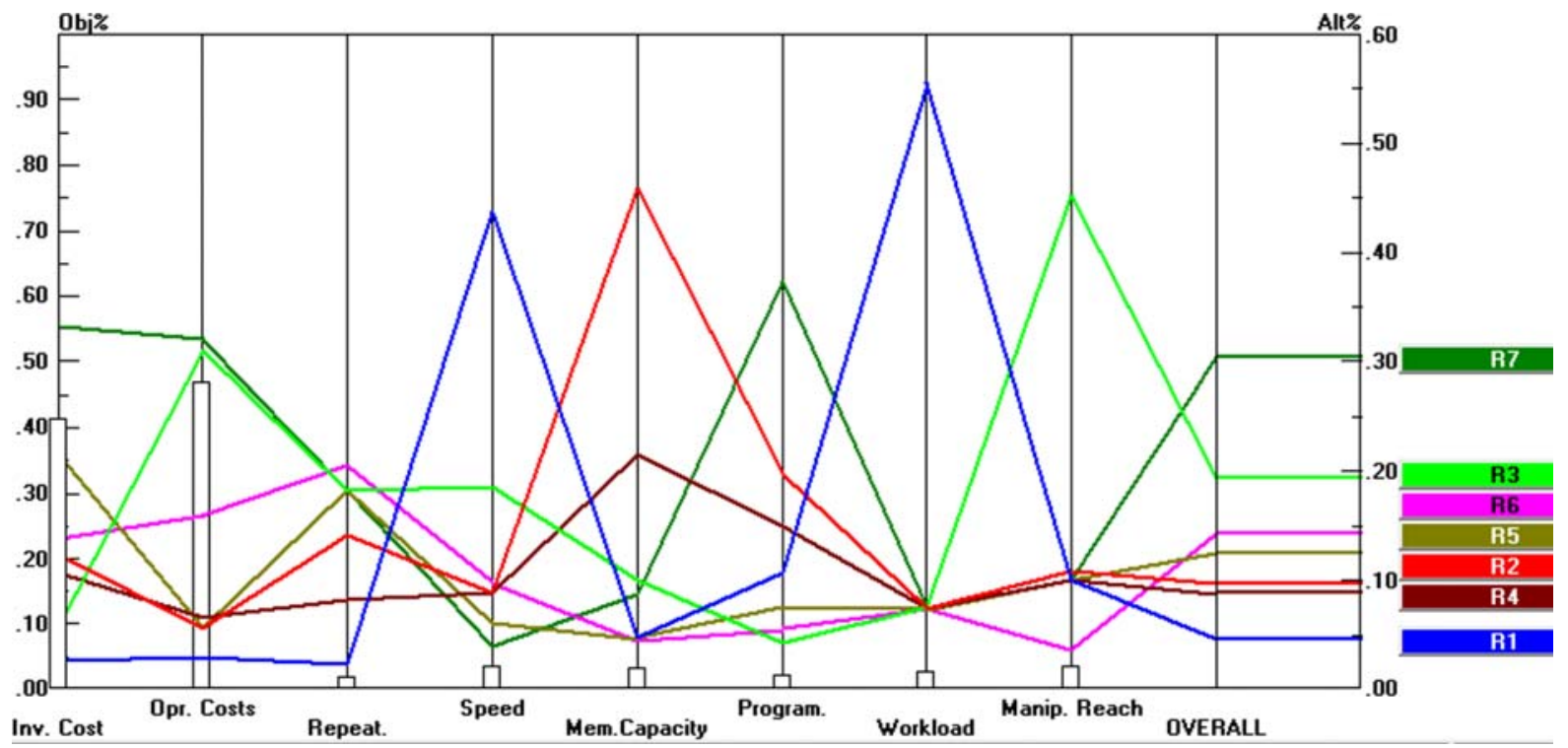

FIG. 5. PERFORMANCE OF ALTERNATIVES WITH RESPECT TO FACTORS

\section{CONCLUSIONS}

While the modern-day manufacturing industries are striving for their market survival and competitive advantages, they have to install highly automated manufacturing systems for speedy, economic and precise operations. Selecting a palletizing robot for the beverage industry production lines depends on different parameters and multiple options are available in the global market. The developing countries like Pakistan need installation of sophisticated systems to reinforce the conventional production units.

This research emphasizes on defining the preferences of Pakistani beverage industry for the available palletizing robot options. Eight influencing factors, screened out by the experts are evaluated in this study and seven robot alternatives are analyzed for each of these factors. The results show that the economic factors have more relative importance as compared to the technical attributes. Among the economic factors, the decision makers are less sensitive to the initial investment cost. However, they assign highest priority to the operating costs. This is because of the reason that in current era of energy crisis the industries are already suffering from higher costs incurred to keep the plants running. Moreover, there is lack of skill manpower to repair the malfunctioning robots thus increasing the repair and maintenance costs. Second iteration of the analysis shows that 'speed' and 'manipulator reach' are the most critical attributes among technical factors while repeatability is the least critical.

A robot manufactured by a Japanese firm has achieved the highest ranking because of the lowest cost and appropriate technical features.Alternative 'R3' is second in the list but its weight is remarkably lower than the first one. Alternative 'R1' manufactured by Swedish firm, despite its good technical features, is lowest in ranking due to its highest cost. It can be concluded from the results that in current perspective of Pakistani beverage industry, palletizing robots manufactured by a Japanese firm are the most suitable. In current economic and industrial crisis, a developing country like Pakistan cannot afford cost intensive robotic solutions and the strategic managers are ready to compromise on the technical aspects.

Mehran University Research Journal of Engineering \& Technology, Volume 36, No. 3, July, 2017 [p-ISSN: 0254-7821, e-ISSN: 2413-7219] 


\section{ACKNOWLEDGEMENTS}

The authors are thankful to strategic mangers of Pakistan

Beverage Industry, for sparing their precious time to provide their expert opinions during different research phases of this study. Authors are also thankful to Hamid Mehmood and Asad Ali, for their collaboration during data collection of this project.

\section{REFERENCES}

[1] Knott, K., and Getto Jr, R.D., "A Model for Evaluating Alternative Robot Systems under Uncertainty”, The International Journal of Production Research, Volume 20, No. 2, pp. 155-165, 1982.
Hwang, C.L., and Yoon, K., "Multiple Attribute Decision Making: Methods and Applications: A State-of-the-Art Survey”, Springer-Verlag, New York, 1981.

Chen, S.J., and Hwang, C.L., "Fuzzy Multiple Attribute Decision Making Methods”, Springer, 1992.

Bhattacharya, A., Sarkar, B., and Mukherjee, S.K., "Material Handling Equipment Selection under MultiCriteria Decision Making (MCDM) Environment”, Industrial Engineering Journal, Volume 31, No. 6, pp. 17-25, 2002.

Saaty, T.L., "The Analytical Hierarchy Process", McGraw-Hill, New York,1980.

Goh, C.H., Tung, Y.C.A., and Cheng, C.H., “A Revised Weighted Sum Decision Model for Robot Selection”, Computers \& Industrial Engineering, Volume 30, No. 2, pp. 193-199, 1996.

Baker, R.C., and Talluri, S., "A Closer Look at the Use of Data Envelopment Analysis for Technology Selection”, Computers \& Industrial Engineering, Volume 32, No. 1, pp. 101-108, 1997.

Parkan, C., and Wu, M.L., "Decision-Making and Performance Measurement Models with Applications to Robot Selection”, Computers \& Industrial Engineering, Volume 36, No. 3, pp. 503-523, 1999.
[9] Bhangale, P.P., Agrawal, V.P., and Saha, S.K., "Attribute Based Specification, Comparison and Selection of a Robot”, Mechanism and Machine Theory, Volume 39, No. 12, pp. 1345-1366, 2004.

[10] Kahraman, C., Çevik, S., Ates, N.Y., and Gülbay, M., "Fuzzy Multi-Criteria Evaluation of Industrial Robotic Systems”, Computers \& Industrial Engineering, Volume 52, No. 4, pp. 414-433, 2007.

[11] Karsak, E.E., "Robot Selection Using an Integrated Approach Based on Quality Function Deployment and Fuzzy Regression”, International Journal of Production Research, Volume 46, No. 3, pp. 723-738, 2008.

[12] Ali, M.K., Akhtar, K., and Jahanzaib, M., "A Hybrid Multidimensional Approach to Select a Country for Global Cement Plant Location”, Meharan University Research Journal of Engineering and Technology, Volume 34, No. 2, pp. 155-168, Jamshoro, Pakistan, April, 2015.

[13] Ali, S.A., Soomro, A.M., and Khizer, A.N., "Design, Implementation and Testing of Master Slave Robotic Surgical System”, Meharan University Research Journal of Engineering and Technology, Volume 34, No. 1, pp. 82-91, Jamshoro, Pakistan, January, 2015.

[14] Daudpoto, J., Memon, A.A., and Hussain, I., “Actuation Characteristics of $0.15 \mathrm{~mm}$ Diameter Flexinol ${ }^{\circledR}$ and Biometal ${ }^{\circledR}$ Wire Actuators for Robotic Applications”, Meharan University Research Journal of Engineering and Technology, Volume 32, No. 1, pp. 147-152, Jamshoro, Pakistan, January, 2012.

[15] Sato, Y., "Administrative Evaluation and Public Sector Reform: An Analytic Hierarchy Process Approach”, International Transactions in Operational Research, Volume 14, No. 5, pp. 445-453, 2007.

[16] Saaty, T.L., "Decision Making with the Analytic Hierarchy Process”, International Journal of Services Sciences, Volume 1, No. 1, pp. 83-98, 2008.

[17] Athawale, V.M., and Chakraborty, S., “A Comparative Study on the Ranking Performance of Some MultiCriteria Decision-Making Methods for Industrial Robot Selection”, International Journal of Industrial Engineering Computations, Volume 2, No. 4, pp. 831-850, 2011. 
[18] Gohar, M., Jahanzaib, M., and Ali, M.K., "Consumer Preferences for Selection of Solar Home Systems in Urban Areas of Pakistan”, Meharan University Research Journal of Engineering and Technology, Volume 33, No. 4, pp. 441-448, Jamshoro, Pakistan, October, 2014.

[19] Tomar, M.M., and Borad, N.N., "Use of AHP Method in Efficiency Analysis of Existing Water Treatment Plants”, International Journal of Engineering, Volume 1, No. 7, pp. 42-51, 2012.

Cheng, E.W., and Li, H., "Construction Partnering Process and Associated Critical Success Factors: Quantitative Investigation”, Journal of Management in Engineering, Volume 18, No. 4, pp. 194-202, 2002.
Lam, K., and Zhao, X., “An Application of Quality Function Deployment to Improve the Quality of Teaching”, International Journal of Quality \& Reliability Management, Volume 15, No. 4, pp. 389-413, 1998.

Wong, J.K., and Li, H., "Application of the Analytic Hierarchy Process (AHP) in Multi-Criteria Analysis of the Selection of Intelligent Building Systems”, Building and Environment, Volume 43, No. 1, pp. 108-125, 2008.

[23] Tahriri, F., Osman, M.R., Ali, A., Yusuff, R.M., and Esfandiary, A., “AHP Approach for Supplier Evaluation and Selection in a Steel Manufacturing Company”, Journal of Industrial Engineering and Management, Volume 1, No. 2, pp. 54-76, 2008. 